\title{
Failure of TRIGR Study Opens Door to Alternative Explanation of T1DM Etiopathology \\ Coad Thomas Dow
}

Mc Pherson Eye Research Institute University of Wisconsin, Madison, USA

"Corresponding author: Coad Thomas Dow, Mc Pherson Eye Research Institute, University of Wisconsin, 9431 WIMR, 1111 Highland Avenue, Madison, WI 53705, USA, Tel: 7158348471; E-mail: ctomdow@gmail.com

Received date: May 05, 2018; Accepted date: May 10, 2018; Published date: May 15, 2018

Copyright: (C) 2018 Dow CT. This is an open-access article distributed under the terms of the Creative Commons Attribution License, which permits unrestricted use, distribution, and reproduction in any medium, provided the original author and source are credited.

\section{Letter to Editor}

The first 2018 JAMA issue reported results of the TRIGR study. The Trial to Reduce Insulin-dependent diabetes mellitus in the Genetically at Risk (TRIGR) study was a 78 center, 15 country study initiated to see if weaning to a hydrolyzed infant formula decreased type 1 diabetes in at-risk children. Rationale prompting the study is that children exclusively breastfed for their initial six months had less chance of developing diabetes than children given cows' milk-based formula. The concept was that cows' milk protein is too complex and that early exposure to it will provoke an autoimmune response in at-risk infants. Both study arms used cows' milk-based formula; one arm had traditionally prepared formula while the other had extensively hydrolyzed formula. The results: "Weaning to a hydrolyzed formula did not reduce the risk of type 1 diabetes in children with an increased disease risk."

An alternative explanation encompassing the rationale for the study was presented in 2006 [1]. It proposed that Mycobacterium avium ss. paratuberculosis (MAP), present in the formula, was the trigger for autoimmune diabetes. It suggested that shared genetic risk for both mycobacterial infection and T1DM offers a permissive environ for latent MAP infection in the infant. Further, MAP's immunodominant heat shock protein 65 (HSP65) cross reacts with pancreatic glutamic acid decarboxylase (GAD) through molecular mimicry [2] resulting in anti-GAD antibodies causing an immune mediated destruction of insulin producing islet cells of the pancreas.
The island of Sardinia has the highest rate of autoimmune diabetes in the world (tied with Finland) and Sechi's lab in Sardinia demonstrated significant MAP presence in T1DM children compared to healthy controls. These findings were duplicated when studies extended onto the Italian mainland [3]. Alarmingly, a study testing 65 samples of infant formula from 18 countries found more than $40 \%$ of the samples were positive for viable MAP [4]. A consensus article from a large MAP conference requests public health intervention for MAP zoonosis [5].

\section{References}

1. Dow CT (2006) Paratuberculosis and Type 1 diabetes - Is this the trigger? Med Hypotheses 67: 782-785.

2. Dow CT (2012) M. paratuberculosis Heat Shock Protein 65 and Human Diseases: Bridging Infection and Autoimmunity. Autoimmune Dis 2012: 150824

3. Masala S, Cossu D, Piccinini S, Rapini N, Massimi A, et al. (2014) Recognition of zinc transporter 8 and MAP3865c homologous epitopes by new-onset type 1 diabetes children from continental Italy. Acta Diabetol 51: 577-585.

4. Grant I, Foddai A, Kunkel B, Collins MT (2014) Detection of Viable Mycobacterium avium subsp. Paratuberculosis (MAP) in Infant Formula. Proceedings of the 12th International Colloquium on Paratuberculosis. Parma, Italy.

5. Kuenstner JT, Naser S, Chamberlin W, Borody T, Graham DY, et al. The Consensus from the Mycobacterium avium ssp. paratuberculosis (MAP) Conference 2017. Front Public Health 5: 208. 